\title{
Raça e Política de Assistência Social: Produção de Conhecimento em Psicologia Social
}

\author{
Érika Cecília Soares Oliveira ${ }^{1}$ \\ ${ }^{1}$ Universidade Federal de Alagoas, AL, Brasil. \\ Luciana Rodrigues $^{3}$ \\ Bruna Moraes Battistelli ${ }^{2}$ \\ ${ }^{2}$ Universidade Federal do Rio Grande do Sul, RS, Brasil. \\ Lilian Rodrigues da Cruz ${ }^{4}$ \\ ${ }^{3}$ Universidade Federal do Rio Grande do Sul, RS, Brasil. $\quad{ }^{4}$ Universidade Federal do Rio Grande do Sul, RS, Brasil.
}

Resumo: Partimos da reflexão acerca das políticas públicas de Assistência Social e como as interfaces raça, racismo e branquitude emergem na produção de conhecimento. Inspiradas na ideia de pluriversalidade questionamos o universo conceitual branco, trazendo como reflexão as produções em Psicologia que se centram em um ideário eurocêntrico, masculinista e heterocentrado. Apresentamos uma discussão sobre o tema da raça e racismo, pensando como estes se articulam tanto na constituição e implementação das políticas públicas, quanto na sua precarização. Para finalizar, afirmamos a necessidade de descolonizar a produção em Psicologia Social, colocar a branquitude em jogo, dissolver a ideia de sujeito universal e assumir a necessidade de pensarmos e publicarmos a partir de uma perspectiva polirracional. Acreditamos que as políticas de produção de saberes e fazeres em Psicologia devem estar atentas à geopolítica do conhecimento, dialogando com diversidades epistêmicas espalhadas em distintas regiões do planeta, sobretudo aquelas do Sul Global.

Palavras-chave: Epistemicídio, Raça, Branquitude, Psicologia Social, Assistência Social.

\section{Race and Social Assistance Policy: Production of Knowledge in Social Psychology}

\begin{abstract}
This paper presents a reflection on public policies for Social Assistance and the way that interfaces such as race, racism and whiteness have appeared in knowledge production. Inspired by the idea of pluriversality, we have questioned the white conceptual universe by bringing reflections on psychology productions focused on a Eurocentric, masculinist, and heterocentered ideology. We present a discussion on race and racism, thinking about the way they have been articulated in the constitution and implementation of public policies as well as in their precariousness. Finally, we state the need to decolonize the production in Social Psychology, in order to bring whiteness into play, dissolve the idea of universal subject, and admit our need to think and publish from a multi-rational perspective. We believe that policies for the production of knowledges and actions in psychology should be attentive to the geopolitics of knowledge, in a dialogue with epistemic diversities spread in different regions over the world, particularly in the Global South.
\end{abstract}

Keywords: Epistemicide, Race,Whiteness, Social Psychology, Social Assistance. 


\title{
Raza y Políticade Bienestar Social: Producción de Conocimiento en Psicología Social
}

\begin{abstract}
Resumen: Se parte de la reflexión sobre las políticas públicas de Bienestar Social e interfaces como la raza, el racismo y la blanquitud surgen en la producción de conocimiento. Inspirados en la idea de la pluriversidad, cuestionamos el universo conceptual blanco, trayendo como reflejo las producciones en psicología que se centran en una idea eurocéntrica, masculinista y heterocéntrica. Presentamos una discusión sobre el tema de la raza y el racismo, pensando cómo se articulan tanto en la constitución y la implementación de las políticas públicas, como en su precariedad.Finalmente, afirmamos la necesidad de descolonizar la producción en Psicología Social, poner en juego la blanquitud, disolver la idea del tema universal y asumir la necesidad de pensar y publicar desde una perspectiva múltiplemente racional. Creemos que la política de producción de conocimiento y las actividades en psicología deben estar atentas a la geopolítica del conocimiento, dialogando con diversidades epistémicas diseminadas en diferentes regiones del planeta, especialmente en las del Sur Global.
\end{abstract}

Palabras clave: Epistemicidio, Raza, Blanquitud, Psicología Social, Asistencia Social.

\section{Sonhos de comida, fome de pensamentos}

Lembro-me de que muitas vezes, quando a mãe cozinhava, da panela subia cheiro algum. Era como se cozinhasse, ali, apenas o nosso desesperado desejo de alimento. As labaredas, sob a água solitária que fervia na panela cheia de fome, pareciam debochar do vazio do nosso estômago, ignorando nossas bocas infantis em que as línguas brincavam de salivar sonho de comida. E era justamente nesses dias de parco ou nenhum alimento que ela mais brincava com as filhas (Evaristo, 2017, p.16-17).

Iniciamos com este trecho do conto "Olhos d'água”, pois constitui o cotidiano de milhares de famílias brasileiras. Aliás, famílias chefiadas por mulheres, em sua maioria negras. Como pensar o trabalho com famílias que passam por privações concretas como a falta de comida? Privações cotidianas inimagináveis no cotidiano de trabalhadoras(es) e pesquisadoras(es), que não precisam negociar com a presença ou ameaça da fome a cada dia. Como escutar e acolher em tempos de acirramento das desigualdades sociais?

Há algum tempo, tais questionamentos têm nos ocupado, tanto no campo das políticas públicas de assistência social como nos espaços acadêmicos. Como produzir conhecimento e intervenções em um campo de negligências de Estado? Como a Psicologia vem produzindo conhecimento acerca das políticas públicas de Assistência Social? E como as interfaces raça, racismo e branquitude emergem na produção de conhecimento? Ainda que a Política Nacional de Assistência Social (Brasil, 2005) seja recente, na última década vários artigos e capítulos de livro foram publicados; logo, temos pistas de que a produção de conhecimento em Psicologia Social no Brasil que vem se constituindo atrelada em sua maioria a autores brancos e homens, que se utilizam como aporte teórico prioritariamente autores europeus, pactuados a partir de uma ideia de sujeito universal desracializado e masculino. Justificamos, desse modo, nosso interesse em discutir este tema tomando como base as políticas de assistência uma vez que elas costumam ser operacionalizadas em territórios pauperizados, generificados e racializados. Não por acaso, as mulheres negras estão entre suas maiores usuárias, tal como abordaremos na próxima seção.

Evidencia-se que a PsicologiaSocial tem produção de conhecimento racializada: é branca e pouco analisa sua branquitude, logo segue produzindo conhecimento a partir de uma concepção de sujeito desracializado (universal), prática que está aserviço de focalizar a brancura como ideal, não conseguindo, por consequência, discutir as diferentes dimensões do privilégio racial (Bento, 2002). Um exercício básico, mas que não exime as pessoas brancas de racismo, é 
revermos privilégios, pensar a responsabilidade das pessoas brancas com as relações étnico-raciais e conseguir assumir o racismo como responsabilidade das pessoas brancas.

O livro "Psicologia social do racismo: estudos sobre branquitude e branqueamento no Brasil" (Bento, 2002), uma coletânea organizada por Iray Carone e Maria Aparecida Bento é um marco importante para a Psicologia no Brasil. Bento (2002) afirma que no Brasil a branquidade é interpretada como branquitude, definida como "traços da identidade racial do branco brasileiro a partir das ideias sobre branqueamento", sendo esse "um processo inventado e mantido pela elite branca brasileira" (p. 25). Concordamos com a autora ao afirmar que a PsicologiaSocial entende que as relações raciais no Brasil apresentam componente narcísico importante, à medida que os grupos que se identificam como brancos se consideram como o modelo e projetam no outro o que não conseguem assumir, pois mancharia/quebraria o modelo. Sendo assim, não haveria motivo para refletir sobre as relações raciais no Brasil, pois as desigualdades raciais focam apenas na população negra; o silêncio e a invisibilidade são instrumentos que protegem os interesses, os privilégios em jogo. A invisibilidade é marca da branquitude. Neste sentido, este ensaio é produzido a partir da indagação: como a questão da raça, racismo e branquitude, constituem modos e processos de produção do conhecimento em Psicologia? Somos mulheres pesquisadoras brancas e negra interessadas na interlocução entre Políticas Públicas e Psicologia Social situando nossa discussão no campo da Assistência Social (uma política que se pauta pela garantia de direitos e diminuição da desigualdade social). Como discutir a Política Nacional de Assistência Social a partir de autoras(es) que produzem e vivem em outro contexto social? Não estamos negando a produção acadêmica que faz uso de autoras(es) brancas(os) europeus/americanos, mas problematizamos a necessidade de deslocarmos nossas produções de referenciais que não se preocupam em racializar suas discussões ${ }^{1}$. O filósofo brasileiro Renato Noguera (2012) afirma que o desafio é fugirmos de uma monorracionalidade, ou seja, é neces- sário acolher a diversidade de narrativas, de lógicas e de epistemologias para que possamos, assim, respeitar as diferenças e constituirmos uma prática pluriversal. A pluriversalidade reconhece a validade de todas as perspectivas, como um exercício policêntrico e perspectivado.

Inspiradas nesta ideia de pluriversalidade, esse trabalho toma como ponto de partida produzir questionamentos sobre o universo conceitual branco (Fanon, 2008; Kilomba, 2016; Césaire, 1978), trazendo como reflexão a ideia de que as produções em Psicologia, nossas escritas, pesquisas e práticas, muitas vezes, são desencarnadas e tomam como chão de suas reflexões um ideário eurocêntrico, masculinista e heterocentrado. Ser desencarnada, neste caso, implica em assumir a postura do "olho de Deus" (Haraway, 1995) como paradigma que orienta as tantas construções que fazem parte desse campo discursivo nomeado Psicologia. Implica, pois, em assumir, muitas vezes, o ponto de vista de lugar nenhum mesmo quando defendemos que devemos falar de algum lugar (Haraway, 1995), quando acreditamos que o conhecimento possui uma geopolítica (Grosfoguel, 2016). O "olho de Deus" nos torna invisíveis, transparentes e, como consequência, presume invisibilidade para os sujeitos para as(os) quais propomos nossas intervenções, nossas pesquisas (Silva, 2009). Corporificar o conhecimento, nesse sentido, teria a ver com a recusa à oposição mente e corpo arraigada na maneira ocidental de pensar (Silva, 2009). Reivindicar uma perspectiva localizada implicaria em identificar as marcas corporais dos discursos que produzimos. Por isso mesmo, a expressão africana ubuntu (Landson-Billings, 2006), que significa "Existo porque nós existimos" suplantaria a máxima cartesiana "Penso, logo existo", uma vez que esta se dá o direito de não se ver como ponto de vista (Santos, 2011) e apaga as condições históricas de sua construção além de colocar somente um sujeito - homem, europeu, branco - com a capacidade de pensar. Ubuntu está diretamente relacionado à ideia de que há uma comunidade de pessoas que necessitam das outras para existirem, para pensarem, para produzirem novos saberes e ressignificarem outros tantos. Trata-se, pois, de uma perspectiva pluriversal (Mignolo, 2004), com pontos de vistas heterogêneos,

\footnotetext{
${ }^{1}$ Somos leitoras/es também de autoras(es) nortecêntricas(os) periféricas(os) que podem ser considerados, tal como ensina Akotirene (2018), do norte-sul global. Norte porque encontram-se em centros hegemônicos de poder e tradução/disseminação de pensamentos e sul porque são negras, lésbicas etc.
} 
que se esparramam num tecido de práticas e saberes não lineares e que considera a diversidade de experiências que estão disponíveis em nossa sociedade de modo não hierarquizado.

São muitas as perguntas que faríamos aqui a partir da ideia de que experiências são constantemente desperdiçadas (Santos, 2008). Desperdício esse institucionalizado pelo modo de funcionar da ciência moderna produzida no Norte Global e reproduzida por nós. Mas uma delas tem a ver com o fato de que seria importante saber quais caminhos percorreríamos se tornássemos vulneráveis os cânones (Denzin, \& Lincoln, 2006). A Psicologia surge como um projeto político com vistas a colocar determinados grupos em seus devidos lugares (Rose, 2011) e, no Brasil, esses grupos são representados justamente por negras(os) e ex-escravizadas(os). Tornar vulneráveis os cânones na Psicologia parece-nos um desafio epistemológico, pois nos faria olhar para a invisibilidade de autoras(es) negras(os) em grande parte das produções feitas por nós. Torcer as teorizações e práticas produzidas pela Psicologia nos colocaria também diante de outras possibilidades, tal como demonstra Santos (2018) que nos conta sobre a riqueza contida nas redes de conexões e cuidados proporcionadas por uma Psicologia do terreiro. Traria, por fim, como possibilidade "dar ouvidos" às vozes que não cessam de serem pronunciadas por usuárias(os) de serviços públicos nos quais atuamos e que nos contam sobre os modos como lidam com suas vidas (e com a morte). Uma pergunta que esse tipo de discussão provoca: que tipo de fissuras suas narrativas produziriam, caso fossem ouvidas efetivamente, sobre o mundo conceitual branco da Psicologia?

A história brasileira com a exploração e a violação dos povos originários e negros é longa e precisa ser revisitada, se o intuito é pensar a produção de conhecimento em Psicologia Social e como essa pode colaborar com o campo das políticas públicas de Assistência Social. Uma aposta em outros referenciais, em outros pontos de partida. Uma tentativa de aproximar ainda mais a experiência acadêmica brasileira com o contexto que vivemos, estabelecendo, prioritariamente, um diálogo com autoras(es) que constroem suas discussões a partir da temática racial como Carneiro (2011), Mbembe (2018a), Schwarcz (2012), Schucman (2012) e Sovik (2014), dentre tantas(os) outras(os).
Assim, apresentamos uma discussão acerca do nosso contexto, centralizando nossa discussão no tema da raça e racismo, pensando como esses se articulam tanto na constituição e implementação de nossas políticas públicas, como na precarização das mesmas. $\mathrm{Ou}$ seja, o racismo não apenas contribui para produção de precarização do trabalho cotidiano, demarcando modos de acolhimento e intervenções que se diferenciam conforme a cor de pele das(os) usuárias(os), como pauta a organização dos serviços socioassistenciais a partir de uma lógica universalizante. Carneiro (2011) nos mostra como a defesa dessa lógica universalizante, que não atenta para as especificidades de cada população, se aproxima do mito da democracia racial, pois "ambas realizam a façanha de cobrir com um manto 'democrático e igualitário' processos de exclusão racial e social que perpetuam privilégios. Postergam, igualmente, o enfrentamento das desigualdades que conformam a pobreza e a exclusão social” (p.99).

Pretendemos, a seguir, debater o modo como as desigualdades (sociais, econômicas, epistêmicas, políticas) participam de contextos como aqueles que se voltam para a produção de políticas sociais e acadêmicas. Essas desigualdades são responsáveis, muitas vezes, por excluir negras e negros das esferas de decisões e de direitos próprias das arenas democráticas e também de locais que poderiam tomá-las(os) como produtoras(es) de saberes. Paralelamente a isso, abordaremos o modo como as mulheres negras são colocadas como responsáveis por gerir e ordenar a miséria produzida por um Estado neoliberal e, paradoxalmente, como os homens negros são colocados na mira deste mesmo Estado que, ao não conseguir regulá-los, opera a partir de um regime soberano, necropolítico, que permite que sejam tacitamente exterminados. Em última instância, queremos abordar o fato de que determinados lugares são socialmente -e forçosamente -designados para alguns grupos; o que põe em questão a ideia de que a democracia é um regime que todo mundo pode acessar em pé de igualdade.

\section{0 racismo à brasileira e as relações com a Política de Assistência Social}

Se o mito deixou de ser oficial, está internalizado. Perdeu seu estatuto científico, porém ganhou o senso comum [...] e o cotidiano (Schwarcz, 2012, p.116). 
Final do século XIX. Dois anos após o processo de "abolição da escravatura" brasileira, Rui Barbosa -então Ministro das Finanças -ordena que todos os registros sobre a escravidão, encontrados nos arquivos nacionais, fossem queimados. Nem todos os arquivos foram eliminados, mas a tentativa de apagamento de um passado de violência e morte continua reverberando em nossos dias atuais. O que essa cena nos permite pensar sobre a discussão que nos propomos nesse texto?

Somos uma nação na qual, frequentemente, circula a ideia de que nos constituímos como um país sem memória. Uma memória fragmentada, editada, por assim dizer, por políticas estatais que nos fazem olhar para determinados eventos e esquecer tantos outros, principalmente aqueles marcados pela violência histórica que atravessa o cotidiano da população negra desse país. É assim que esquecemos o peso e marca que o período de escravização produziu e segue produzindo em nossa sociedade. É assim que nos inventamos como um país onde a mestiçagem teria possibilitado forjar, desde muito cedo, uma sociedade pautada na igualdade racial -igualdade suposta que, hoje, sabemos não ir além da constituição de um mito. É, também, pela via de nossa falta de memória ou, mais precisamente, pela invenção de uma história brasileira onde a característica da mestiçagem, já nos primórdios de nossa brasilidade, nos apontaria como verdadeira a constituição de uma igualdade racial.

Mas se é fato que no contemporâneo conseguimos exercitar nosso pensamento no sentido de desconstruir o mito da democracia racial, apenas reconhecer o racismo nosso de cada dia não é elemento suficiente para que ele deixe de ter um efeito constante em meio as relações que estabelecemos. Pensar a produção de conhecimento no Brasil e sua relação com o campo das políticas públicas aponta a necessidade de pensarmos nossa relação com o tema da escravização da população negra e como constituímos uma memória em relação ao tema. Para problematizar a produção de uma política como a da Assistência Social precisamos discutir como o mito da democracia racial se constitui em uma ferramenta importante da constituição da necropolítica em nosso país.
Como, ao longo das décadas, a Psicologia Social vem produzindo conhecimento sobre este campo? A partir de autoras(es) que não conseguem dar conta da racialização da desigualdade social em nosso país. Somos um país com uma realidade de marcada desigualdade social e altos índices de violência, e os piores marcadores sociais são relegados historicamente à população negra. Dados do Instituto de Pesquisa Econômica Aplicada - IPEA (2011) nos apontam que $70 \%$ dos domicílios que recebem benefícios da Assistência Social são chefiados por uma pessoa negra. Battistelli, Rodrigues e Cruz $(\text { prelo })^{2}$ questionam como, com este dado, ainda não temos nos documentos da Política Nacional de Assistência Social uma discussão sistemática sobre raça e racismo. Uma política produzida prioritariamente por pessoas brancas, a partir de referenciais brancos e pesquisada por pessoas brancas, precisa ser situada a partir do paradigma da branquitude que a constitui, para assim, pensarmos as implicações raciais envolvidas em uma política que visa a garantia de direitos. Precisamos, enquanto pesquisadoras reconhecer, como aponta bell hooks (2017), nossa cumplicidade na aceitação e perpetuação de todos os tipos de parcialidades e preconceitos. Precisamos criar uma sistemática de discussão que consiga ser inclusiva com a história de nosso país, problematizando uma série de violência que pauta a mesma.

Como mencionamos acima, Carneiro (2011) nos alerta quanto ao perigo que corremos quando, no campo das políticas públicas, operamos com a ideia de universalização do sujeito. A mesma afirma que o sujeito universal não tem raça $\mathrm{E}$, assim, o risco é pactuar com o racismo imbuído em um projeto de governo que historicamente nega o Brasil como um país violento e preconceituoso. Se pensarmos na constituição da Política de Assistência, a mesma situa que devemos ver as situações de forma a não sermos preconceituosas(os), que devemos nos atentar as singularidades das situações, se constitui com pouca discussão sobre raça e nenhuma discussão sobre a racialização das desigualdades sociais em seus documentos (Battistelli et al., prelo) ${ }^{3}$.

\footnotetext{
${ }^{2}$ Battistelli, B. M., Rodrigues, L., \& Cruz, L. R. (prelo). O mito da democracia racial e a política de assistência social. In A. Thoma, B. Hillesheim, \& C. Siqueira (Org.), Inclusão, diferença e política públicas. Santa Cruz do Sul, RS: Edunisc.

${ }^{3}$ Battistelli, B. M., Rodrigues, L., \& Cruz, L. R. (prelo). O mito da democracia racial e a política de assistência social. In A. Thoma, B. Hillesheim, \& C. Siqueira (Org.), Inclusão, diferença e política públicas. Santa Cruz do Sul, RS: Edunisc.
} 
Contudo, se no contemporâneo conseguimos exercitar nosso pensamento no sentido de desconstruir o mito da democracia racial, apenas reconhecer o racismo nosso de cada dia não é elemento suficiente para que ele deixe de ter um efeito constante em meio às relações que estabelecemos e em nossas produções. Como nos diz Schwarcz (2012), "a oportunidade do mito se mantém, para além de sua desconstrução racional, o que faz com que no Brasil, mesmo aceitando-se o preconceito, a ideia de harmonia racial se imponha aos dados e à própria consciência da discriminação" (p.111).

Nos jogos de forças do que esquecemos e do que lembramos, a constituição do povo brasileiro se mantém em disputa por espaço e visibilidade em nosso cotidiano, tal como forças díspares em constante luta. Histórias que buscam circular, pelo tecido social, a ideia de que todas(os) somos iguais, de que aqui não somos racistas -embora reconheçamos práticas discriminatórias. Ao mesmo tempo, segue em curso os efeitos de uma estratégia política que, a partir dos anos 1930, encontrou na figura da(o) mestiça(o) a possibilidade de "redenção" da população, através de uma aposta governamental que colocou em curso um projeto de branqueamento da nação. Desse modo, foi em contraponto a perspectivas pessimistas sobre a miscigenação (que poderia trazer falência e degenerescência à nação) que a política brasileira para imigrantes europeus ganhou espaço, tornando-se, para além de outros efeitos políticos e econômicos, uma estratégia efetiva (há um planejamento a longo prazo), que buscava branquear a população. Ou, em outras palavras, extinguir a população negra do país. Quase sem registros de um tempo de escravidão, sonhava-se que os traços da negritude também se dissolvessem no modelo idealizado da branquitude.

Nossa história, assim marcada pela violência, pelo sangue daquelas(es) que durante o "empreendimento colonial" (Mbembe, 2018b) foram sequestradas(os) e traficadas(os) de sua terra natal para se tornarem escravizadas(os) nas Américas, não cessou de trabalhar na manutenção da inferiorização do(s) negro(a)s, de sua exclusão social e da produção de condições precárias de vida para essa população. Se, por um lado, nos tornamos um país mestiço em suas crenças e costumes (cultura), por outro, sustenta-se um racismo invisível e arraigado na exclusão social; negado e criminalizado na esfera da lei, mas perpetuado nas relações privadas da intimi- dade gerando um efeito enorme, de grande impacto na vida pública (Schwarcz, 2012). Assim, pensar em políticas públicas voltadas para a população em situação de pobreza implica em refletirmos sobre os modos como sociedades democráticas distribuem, desigualmente, suas vulnerabilidades (Butler, 2018; Mbembe, 2017). No Brasil, a distribuição da vulnerabilidade é atravessada pelo racismo que pauta nossas relações e pelo mito da democracia racial que incitou o pensamento de que não somos uma nação racista. Implica, pois, em pensarmos no "corpo noturno da democracia” (Mbembe, 2017); o autor afirma que não há democracia sem seu duplo: a democracia contém em si a colônia e a colônia contêm a democracia, muitas vezes mascarada. As democracias modernas têm, historicamente, tolerado uma boa dose de violência política, produzindo comunidades de não semelhantes, aqui entendidas como aquelas que não têm direito a ter direitos. Cai por terra, então, a ideia de que a democracia é uma instância pacificada e desprovida de violência, tendo varrido para longe barbaridades e brutalidades próprias de épocas e regimes anteriores.

Munanga (2017) nos traz uma imagem significativa para compreendermos os efeitos das desigualdades geradas pela produção de uma hierarquização racial que fundamenta nossa história. Para o antropólogo, esse racismo à brasileira sempre foi considerado um “'crime perfeito', pois além de matar fisicamente, alija, pelo silêncio, a consciência tanto das vítimas quanto da sociedade como um todo, brancos e negros" (p. 40). Se a pobreza e a exclusão social têm cor nesse país é, também, sobre as(os) negras(os) que a produção de morte se intensifica. Não é por acaso que há uma concentração de homicídios sobre essa população. De acordo com dados do Atlas da Violência (IPEA, 2018), a taxa de homicídio em relação aos negros atingiu 40,2 no ano de 2016, enquanto que, para o resto da população, o índice não passou de 16 -o que significa que a cada ano, $71,5 \%$ das pessoas assassinadas são pretas ou pardas. Ao acrescentarmos o recorte de idade, constatamos que, além do risco de um jovem negro vir a ser vítima de homicídio ser 2,7 vezes maior que o de um jovem branco, são os jovens negros que possuem um alto índice de mortesdecorrentes de intervenções policiais, $76,2 \%$, entre os anos de 2015 e 2016. Em relação às mulheres, a taxa de homicídios é também maior entre as mulheres negras 5,3 para 3,1 entre as não negras, o 
que gera uma diferença de $71 \%$. Junto a esse dado percebe-se, ainda, que no decorrer dos últimos dez anos houve um aumento de $15,4 \%$ na taxa de homicídios de mulheres negras enquanto que entre as não negras houve queda de $8,0 \%$.

Retomando a discussão sobre o que distinguiria uma democracia, esta teria a ver com a aceitação tácita da regulação dos comportamentos, o governo das condutas, a prevenção da desordem e da violência. Não há, dessa forma, uma "democracia universal" que a todas(os) contemple. O que existem são políticas de Estados que distinguem, claramente, quem é cidadã(ão) e quem não é, distribuindo politicamente e de forma planejada a precariedade para alguns grupos.

Mbembe (2017) afirma que o racismo seria o motor do princípio necropolítico. O racismo é o combustível, o motor, a grande mola propulsora. Ele é a lenha queimando, o fogo que lança fagulhas e faz incendiar, torrar as mãos, os antebraços e braços. Pedaços reduzidos de corpos negros ali dispostos de maneira utilitária, numa denúncia flagrante que nos faz engolir secamente. Necropolítica, então, teria a ver com o fato de que alguns corpos se assemelhariam a "montes de lixo" (Mbembe, 2017), corpos em decomposição, cujos governos são responsáveis por produzir tecnologias que os fazem morrer. E no caso brasileiro, se o racismo se constitui um crime perfeito (Munanga, 2017), precisamos pensar sobre os efeitos do mesmo para as(os) usuárias(os) das políticas públicas, para as(os) estudantes de graduação que se tornarão profissionais, para as(os) pesquisadoras(os) que trabalham com a temática. Ou seja, precisamos pensar a lógica epistemicida (Carneiro, 2005) que perpassa nossa produção de conhecimento, pois o apagamento da população negra vai além da morte do corpo: não conseguimos supor a pessoa negra enquanto produtora de conhecimento.

Nas democracias modernas, alguns segmentos populacionais sofrerão as consequências da deterioração de suas redes de apoio tanto sociais como econômicas, ficando expostos à violência, morte e outros danos (Butler, 2018). Populações que são diferencialmente expostas sofrem com maiores possibilidades de viverem situações de doenças, fome, remoção e vulnerabilidade sem que possam, com isso, terem proteção apropriada. Tal condição politicamente induzida coloca essas pessoas sob a mira de uma gama variada de violências praticadas pelo
Estado ou, quando não praticada por ele, sem reparação suficiente vinda dessa instância. Nas palavras de Butler (2018, p. 153): “[...] estamos dizendo apenas que, sob determinados regimes de poder, alguns grupos são visados mais prontamente que outros, alguns sofrem mais a pobreza do que outros, alguns estão mais expostos à violência policial do que outros". A vulnerabilidade, de acordo com essa autora, seria uma forma de escolher uma população para dizimação. No caso brasileiro, que estamos analisando, essa escolha tem raça, é a população negra a escolhida para sofrer com os piores índices de violência e desigualdade social.

Nesse sentido, há uma questão formulada tanto por Mbembe (2017) como por Butler (2018) que devemos perseguir: em sociedades ditas democráticas, quais grupos serão reconhecidos como humanos, não humanos ou fora do humano? Como já referido, a violência letal no Brasil tem alvo prioritário: homens e mulheres negras que estão no centro do projeto de extermínio que permeia a história do nosso país. O Atlas da Violência (IPEA, 2018) nomeia de juventude perdida a faixa etária entre 15 e 29 anos que sofre com o escalonamento dos casos de violência, tendo os homicídios como causa da morte de 56,5\% desta parcela da população. São jovens negros em sua maioria. De modo geral, o documento aponta que as violências contra a população negra (pretos e pardos) aumentaram em $23,1 \%$ nos últimos 10 anos.

Sobre técnicas de fazer morrer, Bento (2018) ao se referir à população carcerária brasileira, elenca um conjunto delas. Técnicas sistemáticas, racionais, que provocariam a morte daqueles que estão sob tutela estatal, tais como: a comida estragada, o não atendimento médico, a superlotação de celas, aqueles que são presos sem acusação formal e sem sentença.

Quais outras técnicas de morte atingiriam as populações usuárias das políticas de assistência social e que podem ser encontradas em seu dia a dia? Essas técnicas teriam a ver com as supressões de direitos próprias da necropolítica, uma política voltada para matar. Desde a não garantia das seguranças afiançadas pela política, a diminuição de recursos para manutenção dos serviços, não garantia de direitos básicos. Para exemplificar, no contexto de pesquisa de três das autoras, os serviços de Assistência Social da Proteção Básica distribuem o benefício de Vale-transporte Assistencial, para pessoas que não tem dinheiro para pagar a passagem no 
transporte público que custa quatro reais e setenta centavos. Um benefício que deve ser gerido pelas(os) trabalhadoras(es). Às(Aos) usuárias(os), costumeiramente, cabe justificar sua solicitação e demonstrar sua necessidade. $O$ direito de ir e vir sendo negligenciado, já que nunca há benefício para todas(os), e por consequência, o acesso aos serviços como saúde e educação acabam negligenciados. $\mathrm{O}$ acesso à cidade, assim, fica circunscrito para quem pode pagar passagem. Podemos pensar na não garantia de direitos como uma pequena e sistemática morte cotidiana que alija vidas negras.

As mulheres negras são, hegemonicamente, as usuárias de equipamentos públicos como centros de referência de assistência social bem como beneficiárias de programas como o Bolsa Família (PBF) e do Benefício de Prestação Continuada (BPC); vale lembrar que um dos objetivos do PBF é levar a usuária a prescindir do mesmo. O próprio documento enuncia que a usuária da assistência social é responsável pela sua condição denominada vulnerável, cabendo a esta, por lógica, sair dessa situação. Se pensarmos que equipamentos como Centro de Referência de Assistência Social (CRAS) e Centro de Referência Especializado de Assistência Social (CREAS), por meio do atendimento territorializado, realizam ações que tentam prevenir situações compreendidas como sendo de risco e vulnerabilidade, cabe-nos pensar como a distribuição planejada e política das vulnerabilidades é pensada pelas equipes que compõem esses serviços, os efeitos disso no cotidiano de mulheres negras pauperizadas e as formas como o Estado as convoca como coparticipantes no enfrentamento de sua própria pobreza. Podemos afirmar, então, que essas mulheres são duplamente foco das políticas de Assistência Social: responsabilizadas pela situação que vivem e por sair da mesma. Butler (2018) diz que um dos paradoxos do neoliberalismo repousa justamente em sua noção de "responsabilização", por atribuir responsabilidade às populações por sua própria precariedade ou por sua experiência acelerada de precarização. A racionalidade neoliberal, de acordo com essa autora, segue o princípio da autossuficiência, embora não crie condições para que as pessoas possam, de fato, alcançá-la. Em nosso país, usuárias e profissionais da assistência, em sua maioria mulheres e com trabalhos precarizados - muitas vezes contratadas como temporárias, com baixos salários - seriam as "escolhidas" para performarem saídas para as vulnerabilidades produzidas contra elas próprias e, geralmente, com poucas possibilidades de resolução efetiva; tornando-as responsáveis individualmente e convocando-as para fazerem parte de uma lógica neoliberal que as torna ineficazes. Segundo o documento Orientações Técnicas sobre o Serviço de Proteção e Atendimento Integral à Família (Brasil, 2012), a(o) psicóloga(o) deve "provocar impactos na dimensão da subjetividade dos usuários, tendo como diretriz central a construção do protagonismo e da autonomia, na garantia dos direitos com superação das condições de vulnerabilidade social e potencialidades de riscos". É comum ouvirmos relatos de trabalhadoras da assistência social, em eventos que organizamos, descreverem o sofrimento por não atingirem a meta de superar a condição de pobreza das famílias atendidas.

Se nenhum poder político existe sem controle sobre a distribuição de biocódigos de gênero, como afirma Preciado (2018), não deixa de ser interessante pensar que a partir de um biocódigo essencializado - mulheres são vistas como cuidadoras - se assenta grande parte das perspectivas da assistência social, voltadas, em sua maioria, para mulheres pobres e negras e operadas por mulheres brancas e de classe média. Estas últimas formadas em universidades cujo cânone do pensamento em disciplinas de ciências sociais e humanas baseia-se numa estrutura epistêmica orientada no pressuposto de que o conhecimento é produzido por alguns poucos homens de cinco países (Itália, França, Inglaterra Alemanha e Estados Unidos) (Grosfoguel, 2016). Quais os efeitos gerados por essa crença inculcada nas universidades ocidentalizadas que refletirão nas práticas profissionais que, muitas vezes, não tomam as usuárias como interlocutoras e produtoras de diferentes saberes e cosmovisões sobre sua realidade social? Quais saberes são utilizados, em meio a redes visíveis e invisíveis, que nos auxiliariam a pensar em processos de cuidado, saúde, resistência?

Temos que pensar e operar para além dos estereótipos que permeiam a ideia do que seria responsabilidade das mulheres usuárias da Assistência Social: gerir a própria pobreza, ser cobrada pelo Estado por não cumprir com suas condicionalidades (filhos na escolha, pré-natal, profissionalização), parecer incapaz de conduzir a própria vida. Como essas mulheres constituem suas práticas de cuidado 
para consigo mesmas e com seus familiares? O que entendem por proteção? Como proporcionam proteção às(aos) suas(seus)? Enfim, que conhecimentos têm e produzem? As mulheres que frequentam os serviços de Assistência Social são sobreviventes de uma prática genocida: acostumadas a chorar a morte dos filhos e parentes pela violência policial; cansadas de enfrentar o sistema carcerário para manter os laços com os filhos e familiares que se encontram encarcerados. São sobreviventes expostas à impossibilidade de terem suas histórias contadas para além de estereótipos como: negligentes, masoquistas, pobres, barraqueiras...

Vivemos em um país em que a produção de conhecimento e os lugares acadêmicos são ocupados por pessoas brancas. E em decorrência do racismo brasileiro, as questões raciais ainda são tomadas como inexistentes, ou como problema de negras(os) e indígenas. Reconhecer o mito da democracia racial e de que precisamos construir saberes situados não é suficiente para o enfrentamento do racismo à brasileira e da lógica epistemicida que cerca a produção de conhecimento no Brasil.

\section{Sobre algumas possibilidades para a produção de conhecimento em Psicologia}

Segundo Figueiredo e Grosfoguel (2009) somente no final do século XX houve a emergência de um grupo de intelectuais negras(os) que têm contribuído para articular a atividade acadêmica com a prática política. A existência da Associação de Pesquisadores Negros é um avanço, embora, muitas vezes, sejam tratados com desconfiançapor pesquisarem temáticas próximas aos seus contextos e apresentarem uma perspectiva política. Tal proximidade com a temática raça, racismo e branquitude tem servido para desqualificar a produção dessas(es) intelectuais negras(os), a partir do argumento que estão próximos do objeto, perdendo a necessária objetividade para analisar um fenômeno social do qual fazem parte. Mas qual pesquisa não é política? Partimos do pressuposto que a ciência é encarnada.

Piza (1998) é uma das poucas estudiosas brancas brasileiras que se dedicou ao estudo das(os) brancas(os). A mesma afirma que a racialidade da(o) branca(o) é vivida como um círculo concêntrico: a branquitude se expande, se espalha, se ramifica e direciona o olhar da(o) branca(o). Schucman (2012), que tem se dedicado ao estudo da branquitude, afirma que um dos benefícios da mesma é não precisar pensar sobre o significado de ser branca(o) e poder escolher sobre revelar ou não sua própria racialidade. A Psicologia Social, quando pactua com autor(a)s(es) europeu(eia) (s) e brancas(os), escolhe por produzir conhecimento que não consegue reconhecer, pensar e "lidar" com seus privilégios. Descolonizar a produção de conhecimento é acolher diferentes origens, diferentes perspectivas e, principalmente, não utilizar autoras(es) do Norte Global para referendar ou certificar o que é dito por autoras(es) africanas(os), asiáticas(os) ou latino-americanas(os). Descolonizar a produção em Psicologia Social é assim colocar a branquitude em jogo, dissolver a ideia de sujeito universal e assumir a necessidade de pensarmos e publicarmos a partir de uma perspectiva polirracional, pois se continuarmos a produzir e referendar uma mesma política de produção de conhecimento que não reconheça os limites quanto ao uso das(dos) autoras(es) europeus e estadunidenses, estamos produzindo uma prática epistemicída, que pactua com a ideia de que quem pode produzir conhecimento e ser reconhecido por isso são pessoas brancas. Epistemicídio significa o assassinato, a recusa de territórios epistêmicos não hegemônicos (Noguera, 2012).

Carneiro (2011) nos mostra como, no Brasil, o epistemicídio constitui elemento fundamental para o que denomina como dispositivo de racialidade que, ao negar as formas de conhecimento das populações negras, nega também, os próprios sujeitos que as produzem. Instrumento de destituição da racialidade $\mathrm{da}(\mathrm{o})$ outra(o), o epistemicídio persiste em nossa sociedade amparando-se em normas de cognição consensuadas pelos racialmente hegemônicos -no caso as(os) brancas(os)- produzindo um processo de indigência cultural a partir da negação à educação, da inferiorização intelectual, deslegitimação e desqualificação da população negra como sujeito cognoscente. A autora afirma, assim, que a prática epistemicída no Brasil é tão grave quanto o genocídio da população negra, pois impede desde o princípio, a assunção de pessoas negras enquanto produtoras de conhecimento e enquanto sujeitos que podem conhecer (Carneiro, 2011). Renato Noguera, filósofo negro e brasileiro, ao discutir as relações étnico-raciais na educação e no ensino da filosofia, nos ajuda a pensar que, para a resolução de problemas concernentes à nossa realidade brasileira, 
precisamos de outras perspectivas e autoras(es). O autor afirma que o que está em jogo é a colonialidade e o epistemicídio que a acompanha; o que reafirma o lugar de desqualificação de territórios epistêmicos outros, que não os brancos europeus.

Assim, pensar as políticas públicas (no nosso caso, a de Assistência Social) e a Psicologia Social a partir de outros referenciais é produzir conhecimento que respeite nossa história, nossas particularidades e que seja construído para além de uma ideia universal de sujeito. Noguera (2012) afirma que um exercício filosófico supostamente universal é pautado pela invisibilidade da pluriversalidade filosófica, o que podemos pensar também para a Psicologia Social, que precisa questionar suas bases epistemológicas e como vem produzindo conhecimento.

\section{Referências}

Akotirene, C. (2018). O que é interseccionalidade. Belo Horizonte, MG: Letramento.

Bento, B. (2018). Necrobiopoder: quem pode habitar o estado-nação? Cadernos Pagu, Campinas, n. 53, el85305. https://doi.org/10.1590/18094449201800530005

Bento, M. A, S. (2002). Branqueamento e branquitude no Brasil. In I. Carone, \& M. A. S. Bento. Psicologia social do racismo: Estudos sobre branquitude e branqueamento no Brasil (pp. 25-58). Petrópolis, RJ: Vozes.

Brasil (2012). Ministério do Desenvolvimento Social e Combate à Fome. Secretaria Nacional de Assistência Social. Orientações técnicas sobre o Serviço de Proteção e Atendimento Integral à Família - PAIF.

Brasil. (2005). Ministério do Desenvolvimento Social e Combate à Fome. Secretaria Nacional de Assistência Social. Política nacional de assistência social: PNAS/2004: norma operacional básica NOB/SUAS. Brasília, DF: o autor. Recuperado de: http://bibspi.planejamento.gov.br/bitstream/handle/123456789/1034/PNAS2004. pdf? sequence $=1$ \&isAllowed $=\mathrm{y}$

Butler, B. (2018). Corpos em aliança e a política das ruas: Notas para uma teoria performativa da assembleia. Rio de Janeiro, RJ: Civilização Brasileira.

Carneiro, A. S. (2005). A construção do outro como não-ser como fundamento do ser (Tese de doutorado). Faculdade de Educação, Universidade de São Paulo, São Paulo, SP, Brasil.

Carneiro, S. (2011). Racismo, sexismo e desigualdade no Brasil. São Paulo: Selo Negro.

Cesairé, A. (1978). Discurso sobre o colonialismo. Lisboa: Sá da Costa.

Denzin, N. K., \& Lincoln, Y. S. (2006). O planejamento da pesquisa qualitativa: Teorias e abordagens. Porto Alegre, RS: Artmed.

Evaristo, C. (2017). Olhos d'água. Rio de Janeiro, RJ: Pallas.

Fanon, F. (2008). Pele negra, máscaras brancas. Salvador, BA: EDUFBA.

Figueiredo, A., \& Grosfoguel, R. (2009). Racismo à brasileira ou racismo sem racistas: colonialidade do poder e a negação do racismo espaço universitário. Sociedade e Cultura, 2(3), 223-234. https://doi.org/10.5216/sec. v12i2.9096

Grosfoguel, R. (2016). A estrutura do conhecimento nas universidades ocidentalizadas: racismo/sexismo epistêmico e os quatro genocídios/epistemicídios do longo século XVI. Revista Sociedade e Estado, 31(1), 25-49. https://doi.org/10.1590/S0102-69922016000100003

Haraway. D. (1995). Saberes localizados: a questão da ciência para o feminismo e o privilégio da perspectiva parcial. Cadernos Pagu, (5), 7-41.

Hooks, B. (2017). Ensinando a transgredir:A educação como prática de liberdade (2a ed.). São Paulo, SP: Wmf Martins Fontes.

Instituto de Pesquisa Econômica Aplicada - IPEA. (2011). Retrato das desigualdades de gênero e raça (4a ed.). Brasília, DF: o autor.

Instituto de Pesquisa Econômica Aplicada - IPEA. (2018). Atlas da violência 2018. Rio de Janeiro, RJ: o autor.

Kilomba, G. (2016). A máscara. Caderno de Literatura em Tradução, (16), 171-180. 
Landson-Billings, G. (2006). Discursos racializados e epistemológicas étnicas. In: N. K.Denzin, Y. S. Lincoln, O planejamento da pesquisa qualitativa: Teorias e abordagens (pp. 259-79). Porto Alegre, RS: Artmed.

Mbembe, A. (2017). Políticas de inimizade. Lisboa: Antígona.

Mbembe, A. (2018a). Necropolítica. São Paulo, SP: n-1 Edições.

Mbembe, A. (2018b). Crítica da razão negra. São Paulo, SP: n-1 Edições.

Mignolo, W. D. (2004). Os esplendores e misérias da "ciência": colonialidade, geopolítica do conhecimento e pluri-versalidade epistêmica. In B. S. Santos, Conhecimento prudente para uma vida decente: Um discurso sobre as ciências revisitados. São Paulo, SP: Cortez.

Munanga, K. (2017). As ambiguidades do racismo à brasileira. In Kon, N. M., M. L. Silva, \& C. C. Abud (Orgs.), O racismo e o negro no Brasil: Questões para a psicanálise (pp. 33-44). São Paulo, SP: Perspectiva.

Noguera, R. (2012). Denegrindo a educação: Um ensaio filosófico para uma pedagogia da pluriversalidade. Revista Sul-Americana de Filosofia e Educação, (18), 62-73.

Piza, E. (1998). O caminho das águas: Personagens femininas negras escritas por mulheres brancas. São Paulo, SP: Edusp.

Preciado, P. B. (2018). Testo junkie:Sexo, drogas e biopolítica na era farmacopornográfica. São Paulo: n-1 Edições.

Rose, N. (2011). Psicologia como ciência social. In: N. Rose, Inventando nossos selfs: Psicologia, poder e subjetividade (pp. 98-116). Petrópolis, RJ: Vozes.

Santos, A. (2018). Candomblé, psicologia do terreiro e construção de rede. Cadernos Deligny, 1(1), 135-143.

Santos, B. S. (2008). Para uma sociologia das ausências e uma sociologia das emergências. In B. S. Santos, A gramática do tempo (pp. 237-260). São Paulo, SP: Cortez.

Santos, B. S. (2011). Da ciência moderna ao novo senso comum. In B. S. Santos, A crítica da razão indolente:Contra o desperdício da experiência (pp. 55-117). São Paulo, SP: Cortez.

Schucman, L. V. (2012). Entre o "encardido", o "branco" e o "branquíssimo": Raça, hierarquia e poder na construção da branquitude paulistana (Tese de doutorado). Instituto de Psicologia, Universidade de São Paulo, São Paulo, SP, Brasil.

Schwarcz, L. M. (2012). Nem preto nem branco, muito pelo contrário: Cor e raça na sociabilidade brasileira. São Paulo, SP: Claro Enigma.

Silva, M. R. (2009). Refigurando monstros: a perspectiva parcial de Donna Haraway como crítica da ciência (Dissertação de mestrado). Instituto de Medicina Social, Universidade Estadual do Rio de Janeiro, Rio de Janeiro, RJ, Brasil.

Sovik, L. (2014). Preto no branco: Stuart Hall e a branquitude. Revista da Associação Brasileira de Pesquisadores/as Negros/as, 6(13), 162-174.

Érika Cecília Soares Oliveira

Docente do Instituto de Psicologia e do Programa de Pós-Graduação em Psicologia da Universidade Federal de Alagoas. Maceió - AL. Brasil.

E-mail: erika.oliveira@ip.ufal.br

http://orcid.org/0000-0003-4877-0971

\section{Bruna Moraes Battistelli}

Doutoranda no Programa de Pós-Graduação em Psicologia Social e Institucional da Universidade Federal do Rio Grande do Sul. Porto Alegre - RS. Brasil. O presente trabalho foi realizado com apoio da Coordenação de Aperfeiçoamento de Pessoal de Nível Superior - Brasil (CAPES) - Código de financiamento 001

E-mail: brunabattistelli@gmail.com

https://orcid.org/0000-0003-0973-0934 


\section{Luciana Rodrigues}

Docente do Departamento de Psicología Social e Institucional da Universidade Federal do Rio Grande do Sul. Porto Alegre-RS. Brasil.

E-mail:lurodrigues.psico@gmail.com

D https://orcid.org/0000-0003-0061-1402

\section{Lilian Rodrigues da Cruz}

Docente do Departamento de Psicologia Social e Institucional e do Programa de Pós-Graduação em Psicologia Social e Institucional da Universidade Federal do Rio Grande do Sul. Porto Alegre - RS. Brasil

E-mail: lilian.rodrigues.cruz@gmail.com

(iD) https://orcid.org/0000-0002-1850-3023

Endereço para envio de correspondência:

Av. Lourival Melo Mota, s/n, Campus A.C. Simões, Tabuleiro do Martins, Instituto de Psicologia, Maceió, AL,

Brasil, CEP 57072-900,

Recebido:24/06/2019

Aceito: 19/07/2019

Received:06/24/2019

Approved: 07/19/2019

Recibido:24/06/2019

Aceptado: 19/07/2019

Como citar: Oliveira, E. C. S., Battistelli, B. M., Rodrigues, L., \& Cruz, L. R. (2019). Raça e política de assistência social: Produção de conhecimento em Psicologia Social. Psicologia: Ciência e Profissão, 39(n.spe 2), 141-152. https://doi.org/10.1590/1982-3703003225556

How to cite: Oliveira, E. C. S., Battistelli, B. M., Rodrigues, L., \& Cruz, L. R. (2019). Race and social assistance policy: Production of knowledge in Social Psychology. Psicologia: Ciência e Profissão, 39(n.spe 2), 141-152.

https://doi.org/10.1590/1982-3703003225556

Cómo citar: Oliveira, E. C. S., Battistelli, B. M., Rodrigues, L., \& Cruz, L. R. (2019). Raza y política de bienestar social: Producción de conocimiento en Psicología Social. Psicologia: Ciência e Profissão, 39(n.spe 2), 141 -152. https://doi.org/10.1590/1982-3703003225556 